\title{
Karakter Morfologi Fungiasp. Di Pulau Mamburit,Kabupaten Sumenep, Jawa Timur, Indonesia
}

\author{
Morphological Characters of Fungia sp. at Mamburit Island, Sumenep Regency, East Java, Indonesia \\ Sawiya ${ }^{1)}$, Diana Arfiati ${ }^{2)}$, Guntur $^{3)}$, Heri Ariadi $\left.{ }^{4}\right)^{*}$, dan Abdul Wafi ${ }^{1)}$ \\ 1)Departemen Budidaya Perikanan, Fakultas Sains dan Teknologi, Universitas Ibrahimy, \\ Situbondo. \\ 2) Jurusan Manajemen Sumberdaya Perairan, Fakultas Perikanan dan IImu Kelautan, Universitas \\ Brawijaya, Malang. \\ 3)Jurusan Pemanfaatan Sumberdaya Perikanan, Fakultas Perikanan dan IImu Kelautan, \\ Universitas Brawijaya, Malang. \\ 4)Program Studi Budidaya Perairan, Fakultas Perikanan, Universitas Pekalongan, Pekalongan.
}

*Penulis korespondensi : email : ariadi heri@yahoo.com

(Diterima Juni 2021/ Disetujui Agustus 2021)

\begin{abstract}
Fungia sp. is a genus from Fungiidae family which mostly solitary coral reef, inherent and freeliving, and can move to another place. Aim of this study was to analyze the morphological characters of Fungia sp. which found at Mamburit Island, Sumenep District, East Java, Indonesia. Survey method was obtained in this study by random sampling. The total sample was conducted two different species with two times of repetition in every station. Stations were selected in this study were Leeward I, Leeward II, Windward I, Windward II. The data were analysis descriptively. Based on repetition, the selected coral reef has great similarities to morphological characteristics at all sampling stations. Fungia fungites ("a" group coral) and Fungia scutaria ("b" group coral) were species of Fungia sp. spesies obtained from morphology predict coral analysis results.
\end{abstract}

Keywords: Fungia fungites, Fungia scutaria, Fungia sp., Fungiidae, Mamburit.

\begin{abstract}
ABSTRAK
Fungia sp. merupakan genus dari famili Fungiidae yang sebagian besar terumbu karang soliter, melekat dan hidup bebas, serta dapat berpindah ke tempat lain. Tujuan penelitian ini adalah menganalisis karakter morfologi jamur Fungia sp. yang ditemukan di Pulau Mamburit, Kabupaten Sumenep, Jawa Timur, Indonesia. Metode survei diperoleh dalam penelitian ini dengan cara random sampling. Jumlah sampel dilakukan dua spesies berbeda dengan dua kali pengulangan di setiap stasiun. Stasiun yang dipilih dalam penelitian ini adalah Leeward I, Leeward II, Windward I, Windward II. Data dianalisis secara deskriptif. Berdasarkan pengulangan, terumbu karang yang dipilih memiliki kemiripan yang besar dengan karakteristik morfologi di semua stasiun pengambilan sampel. Jamur Fungia (karang kelompok "a") dan Fungia scutaria (karang kelompok "b") adalah jenis spesiesFungia sp. yang diperoleh dari hasil analisis prediksi morfologi karang.
\end{abstract}

Kata kunci: Fungia fungites, Fungia scutaria, Fungia sp., Fungiidae, Mamburit.

\section{PENDAHULUAN}

Fungia sp. merupakan salah satu terumbu karang yang tergolong dalam karang jamur atau Scleractinia, jenis karang ini banyak diketemukan melimpah di perairan Indo-Pasifik. Jenis karang ini dicirikan denganhidup bebas, banyak diketemukan menempel pada spesimen laut dan memiliki

To Cite this Paper: Sawiya., Arfiati, D., Guntur., Ariadi, H., Wafi, A., 2021. Karakter Morfologi Fungiasp. Di Pulau Mamburit, Kabupaten Sumenep, Jawa Timur, Indonesia .Samakia: Jurnal Ilmu Perikanan, 12 (2): 116-130.

Journal Homepage: $\underline{\text { https://journal.ibrahimy.ac.id/index.php/JSAPI }}$ 
kemampuan untuk menghindari interaksi dengan organisme pesaing yang dapat membahayakan hidupnya (Cairns, 1984, Hoeksema 1989, 1990, 2009, Gittenberger et al., 2011), Benzoni et al., 2012). Fungia sp. juga memiliki peran penting sebagai habitat dan simbion organisme laut seperti zooxanthella, ikan, kepiting, bivalvia, teritip, moluska, krustasea, dan cacing (Hoeksema et al., 2012; Stella et al., 2010). Faktor nutrien alam akan mempengaruhi sebara habitat organisme akuatik (Ariadi et al, 2020).

Pulau Mamburit merupakan salah satu pulau dengan aktivitas pariwisata yang tinggi seperti snorkeling dan diving. Sebagian besar masyarakat Mamburit hidup dengan menggantungkan hidupnya dari hasil tangkapan ikan. Kawasan pulau Mamburit terbagi menjadi dua kategori, yaitu Windward dan Leeward. Pulau Mamburit memiliki pantai yang landai dan berpasir putih dengan persentase ekosistem terumbu karang yang baik. Akan tetapi, identifikasi jenis terumbu karang khususnya genus Fungia sp. Masih kurang, dimana identifikasi diperlukan untuk mengetahui keanekaragaman terumbu karang yang hidup di wilayah tersebut dengan tetap menjaga kelestarian ekosistem terumbu karang. Zawada dkk. (2019), menjelaskan bahwa morfologi koloni karang memiliki peran penting dalam kinerja biologi dan ekologi, termasuk implikasinya sebagai insinyur ekosistem. Berdasarkan informasi tersebut, kelimpahan Fungia sp. pengaruh keragaman karakter pada masing-masing spesies, sehingga tujuan dari penelitian ini adalah menganalisis karakteristik morfologi jamur Fungia sp. sebagai langkah awal dalam proses identifikasi Fungia sp. di Pulau Mamburit, Kabupaten Sumenep, Jawa Timur, Indonesia.

\section{MATERI DAN METODE}

\section{Lokasi Pengambilan Sampel}

Penelitian ini dilakukan di empat stasiun di Pulau Mamburit, Kabupaten Sumenep, Jawa Timur, Indonesia. Stasiun 1 adalah Leeward I (S 06050'30.96 "dan E 115013'17.25), Stasiun 2 adalah Leeward II (S 06050'40.64" dan E 115012'59.37), Stasiun 3 adalah Windward I (S 06050'27.24 "dan E 115013 '01 .74), dan Stasiun 4 adalah Windward II (S 06050'17.91 "dan E 115013'10.88)

\section{Persiapan Sampling}

Dipilih dua jenis karang yang berbeda secara acak berdasarkan pembedaan morfologi (tidak terlihat) pada setiap stasiun dengan pengulangan sebanyak dua kali. Jumlah sampel yang diambil di setiap stasiun sebanyak 4 terumbu karang. Pengamatan sampel dilakukan secara langsung dengan menggunakan alat selam pada kedalaman 3 meter dengan Global Positioning System (GPS) untuk mengetahui lokasi komunitas terumbu karang. Sampel yang dipilih dibawa ke permukaan (darat) kemudian direndam ke dalam etanol $96 \%$ secara teknis dan disimpan selama 7 hari di dalam cool box sehingga jaringan dan kerangka dipisahkan. Sodium hipoklorit ditambahkan untuk memutihkan karang dan kemudian dikeringkan di bawah sinar matahari. Analisis morfologi diukur dengan menggunakan calliper $(0,01 \mathrm{~mm})$. Penelitian ini dilakukan pada bulan Juli hingga Oktober 2017.

\section{Analisis Morfologis}

Analisis morfologi dimodifikasi diikuti oleh Budd dan Stolarski (2009). Ciri-ciri Fungia sp. Morfologi yang digunakan adalah panjang corallite, lebar corallite, kedalaman caliceal, tebal dinding corallite, panjang septa terpendek, panjang septa terpanjang, jumlah septa per corallite. Jarak gigi septum, jarak gigi, kolumela, permukaan koloni, bentuk gigi septa, tepi septa, dan bentuk koloni.

\section{Analisis data}

Data dianalisis secara deskriptif pada setiap sampel yang dipilih di setiap stasiun pengambilan sampel.

\section{HASIL DAN PEMBAHASAN}

Berdasarkan pengamatan diperoleh dua jenis karang yang dikodekan oleh karang "a" dan karang "b". Karakter morfologi pada masing-masing karang menunjukkan tidak jauh berbeda di setiap stasiun pengambilan sampel. Data disajikan pada Tabel 1. Berdasarkan paparan data pada Tabel 1. ditunjukan beberapa perbedaan nilai masing-masing individu karang, fenomena tersebut dipengaruhi oleh ukuran terumbu yang diambil berbeda. Sehingga terjadi sedikit perbedaan nilai

To Cite this Paper: Sawiya., Arfiati, D., Guntur., Ariadi, H., Wafi, A., 2021. Karakter Morfologi Fungiasp. Di Pulau Mamburit, Kabupaten Sumenep, Jawa Timur, Indonesia .Samakia: Jurnal IImu Perikanan, 12 (2): 116-130. 
pada karakter morfologi masing-masing terumbu karang. Perbedaan ini kemungkinan besar disebabkan adanya perbedaan sebaran habitat alami masing-masing karang di perairan.

Salah satu faktor ekologi perairan yang berpengaruh adalah kondisi parameter kualitas pada habitat karang itu sendiri. Parameter kualitas air merupakan indikator alamiah perairan yang memiliki peran penting terhadap sebaran ekologi dan habitat biota di ekosistem perairan bersangkutan (Ariadi et al, 2019). Fluktuasi kualitas air ini nantinya akan berpengaruh pula terhadap berbagai proses fisika dan kimia yang terjadi di perairan (Ariadi et al, 2020). Faktor cuaca dan anomali iklim akan berpengaruh juga terhadap tingkat diversitas karang yang ada di suatu perairan.

Tabel 1. Karakteristik Morfologi Karang Terpilih yang Ditemukan di Pulau Mamburit

\begin{tabular}{|c|c|c|c|c|c|c|c|c|c|}
\hline \multirow[t]{2}{*}{ Code } & \multirow{2}{*}{$\begin{array}{l}\text { Morphological } \\
\text { Characteristics }\end{array}$} & \multicolumn{2}{|c|}{$\begin{array}{c}\text { Leeward } \\
\text { I }\end{array}$} & \multicolumn{2}{|c|}{$\begin{array}{c}\text { Leeward } \\
\text { II }\end{array}$} & \multicolumn{2}{|c|}{$\begin{array}{c}\text { Windward } \\
\text { I }\end{array}$} & \multicolumn{2}{|c|}{$\begin{array}{c}\text { Windward } \\
\text { II }\end{array}$} \\
\hline & & 1 & 2 & 1 & 2 & 1 & 2 & 1 & 2 \\
\hline & Corallite length $(\mathrm{cm})$ & 8.9 & 8.5 & 9.5 & 8.9 & 6.5 & 7.4 & 9.9 & 11.2 \\
\hline \multirow[t]{14}{*}{ A } & Corallite width $(\mathrm{cm})$ & 8.5 & 7.9 & 8.5 & 8.4 & 6.3 & 6.9 & 9.5 & 9.9 \\
\hline & Calical depth (cm) & 0.3 & 0.3 & 0.4 & 0.3 & 0.3 & 0.3 & 0.4 & 0.3 \\
\hline & Corallite wall thickness $(\mathrm{cm})$ & 0.4 & 0.2 & 0.5 & 0.5 & 0.4 & 0.4 & 0.5 & 0.5 \\
\hline & Shortest septa length $(\mathrm{cm})$ & 1.5 & 0.8 & 0.4 & 0.5 & 0.4 & 0.5 & 0.7 & 0.6 \\
\hline & Longest septa length (cm) & 4.9 & 4.1 & 4.4 & 4.4 & 3.5 & 3.7 & 4.3 & 4.5 \\
\hline & Nnumber of septa per & & & & & & & & \\
\hline & corallite & 272 & 200 & 396 & 286 & 179 & 205 & 269 & 332 \\
\hline & Septal teeth distance $(\mathrm{cm})$ & 0.3 & 0.1 & 0.1 & 0.1 & 0.1 & 0.2 & 0.1 & 0.1 \\
\hline & Teeth distance $(\mathrm{cm})$ & 0.1 & 0.1 & 0.1 & 0.1 & 0.1 & 0.1 & 0.1 & 0.1 \\
\hline & Collumela $(\mathrm{cm})$ & 1.9 & 1.8 & 1.2 & 1.1 & 1.2 & 1.3 & 0.9 & 1.1 \\
\hline & Colony surface & \multicolumn{8}{|c|}{ Flat } \\
\hline & The shape of septa teeth & \multicolumn{8}{|c|}{ Pointed and sharp } \\
\hline & Septa margins $(\mathrm{cm})$ & 0.1 & 0.1 & 0.2 & 0.1 & 0.2 & 0.2 & 0.2 & 0.2 \\
\hline & Colony form & \multicolumn{8}{|c|}{ Circle } \\
\hline & Corallite length $(\mathrm{cm})$ & 12.5 & 12.8 & 11.2 & 8.5 & 11.5 & 9.9 & 12.3 & 10.5 \\
\hline \multirow[t]{13}{*}{ B } & Corallite width $(\mathrm{cm})$ & 8.7 & 7.8 & 9.5 & 6.5 & 7.7 & 7.2 & 7.5 & 8.5 \\
\hline & Calical depth (cm) & 0.4 & 0.3 & 0.2 & 0.3 & 0.3 & 0.3 & 0.3 & 0.2 \\
\hline & Corallite wall thickness $(\mathrm{cm})$ & 0.3 & 0.4 & 0.7 & 0.6 & 0.6 & 0.4 & 0.7 & 0.1 \\
\hline & Shortest septa length $(\mathrm{cm})$ & 0.5 & 0.4 & 0.6 & 0.2 & 0.4 & 0.5 & 0.5 & 0.3 \\
\hline & Longest septa length $(\mathrm{cm})$ & 4.5 & 8.9 & 5.5 & 3.9 & 5.4 & 4.4 & 5 & 5.5 \\
\hline & $\begin{array}{l}\text { Nnumber of septa per } \\
\text { corallite }\end{array}$ & 264 & 288 & 343 & 200 & 352 & 302 & 305 & 308 \\
\hline & Septal teeth distance $(\mathrm{cm})$ & 0.5 & 0.3 & 0.1 & 0.2 & 0.2 & 0.1 & 0.1 & 0.1 \\
\hline & Teeth distance $(\mathrm{cm})$ & 0.3 & 0.1 & 0.3 & 0.1 & 0.3 & 0.2 & 0.3 & 0.4 \\
\hline & Collumela $(\mathrm{cm})$ & 1 & 0.6 & 1.1 & 1.2 & 1.1 & 1.1 & 1.1 & 0.8 \\
\hline & Colony surface & \multicolumn{8}{|c|}{ Slightly hilly } \\
\hline & The shape of septa teeth & \multicolumn{8}{|c|}{ Blunt } \\
\hline & Septa margins $(\mathrm{cm})$ & & & & & & & & 0 . \\
\hline & Colony form & 0.2 & & .2 & .2 & 0.2 & 0.1 & 0.2 & 2 \\
\hline
\end{tabular}

Karakteristik morfologi ditunjukkan pada Gambar 1. Gambar tersebut menunjukkan bahwa kedua sampel tersebut termasuk dalam famili Fungiidae genus Fungia sp. secara morfologis. Karang genus Fungia sp. Adalah jenis karang yang biasa sering dijumpai pada daerah dengan kondisi suhu perairan yang hangat.

To Cite this Paper: Sawiya., Arfiati, D., Guntur., Ariadi, H., Wafi, A., 2021. Karakter Morfologi Fungiasp. Di Pulau Mamburit, Kabupaten Sumenep, Jawa Timur, Indonesia .Samakia: Jurnal IImu Perikanan, 12 (2): 116-130. 


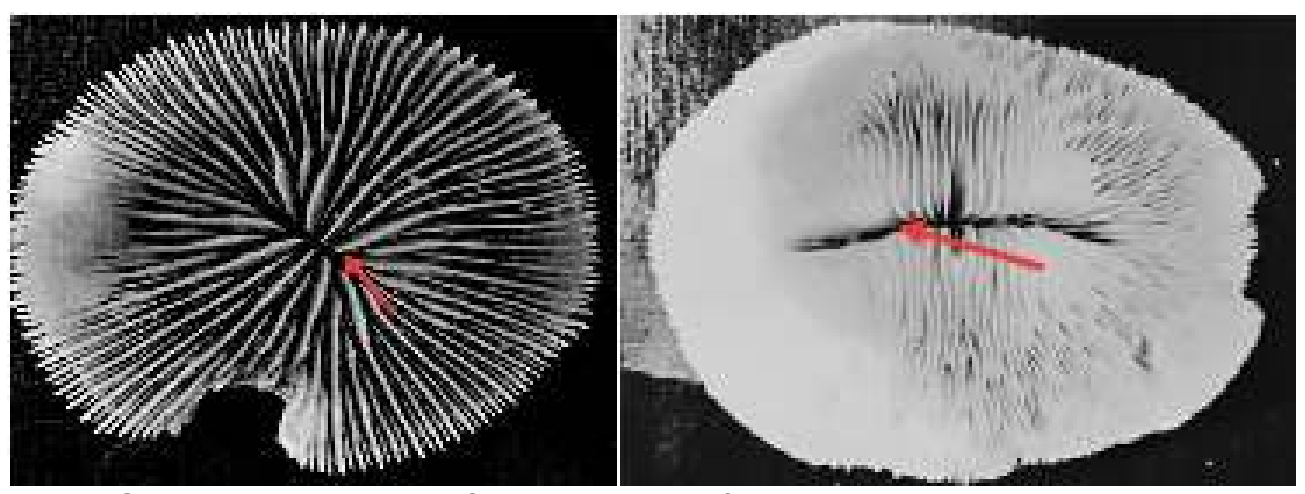

Gambar 2. Bentuk morfologi A) Fungia fungites; B) Fungia scutaria

Hasil penelitian secara karakter morfologi yang menunjukan bahwa karang ini termasuk famili Fungiidae genus Fungia sp. Didukung oleh pernyataan Richards (2018), bahwa bentuk koloni Fungiidae berbentuk cakram, melingkar atau memanjang, pipih, gigi septum runcing dan soliter, susunan kalis berbentuk bulat hingga oval. Pada karang "a" diduga sebagai jamur Fungia karena memiliki ciri morfologi tertentu yang mirip dengan jamur Fungia. Meskipun kode karang "a" dan "b" merupakan genus yang sama yaitu Fungiidae, namun memiliki karakteristik yang berbeda antara karang "a" dan "b". Bentuk koloni karang "a" datar sedangkan karang "b", bentuk koloni berbentuk lonjong dan diduga sebagai Fungia scutaria. Hal ini didukung oleh Majuro Atoll (2017), jamur jamur memiliki polip melingkar, gigi berbentuk segitiga dengan tulang rusuk di tengah, gigi besar dan runcing rata, Walaupun jamur jamur memiliki polip lonjong, septa tebal dan kuat, polip melengkung lemah. Karakteristik perbedaan bentuk pada organisme akuatik, sangat erat dipengaruhi oleh karakter fisika dan kimia habitat lingkungan perairannya

\section{KESIMPULAN}

Hasil karakter morfologi pada perbedaan kedua sampel diperoleh bahwa pada semua stasiun pengambilan sampel ditemukan dua jenis karang yaitu famili Fungiidae, genus Fungia, dan karang "a" yang diduga sebagai jamur Fungia; Karang "b" diperkirakan sebagai Fungia scutaria. Pernyataan tersebut merupakan asumsi sementara, sehingga perlu dilakukan analisis lebih lanjut seperti uji molekuler untuk memastikannya.

\section{DAFTAR PUSTAKA}

Ariadi, H., Fadjar M., Mahmudi M., Supriatna., 2019. The relationships between water quality parameters and the growth rate of white shrimp (Litopenaeus vannamei) in intensive ponds. AACL Bioflux 12(6): 2103-2116.

Ariadi, H., Wafi A., Supriatna., 2020. Hubungan Kualitas Air Dengan Nilai FCR Pada Budidaya Intensif Udang Vanname (Litopenaeus vannamei).Samakia: Jurnal Ilmu Perikanan 11(1) : 44-50.

Ariadi, H., Pandiangan I.A.H., Soeprijanto A., Maemunah Y., Wafi A., 2020. Effectiveness of Using Pakcoy (Brassica rapa L.) and Kailan (Brassica oleracea) Plants as Vegetable Media for Aquaponic Culture of Tilapia (Oreochromis sp.). Journal of Aquaculture Development and Environment 3(2) : 156-162.

Ariadi, H., Wafi A., Musa M., Supriatna., 2021. Keterkaitan Hubungan Parameter Kualitas Air Pada Budidaya Intensif Udang Putih (Litopenaeus vannamei).Samakia: Jurnal IImu Perikanan 12(1): 18-27.

Benzoni, F., Arrigoni, R., Stefani, F., Reijnen, B., Montano, S., \& Hoeksema, B. 2012. Phylogenetic position and taxonomy of Cycloseris explanulata and C. wellsi (Scleractinia: Fungiidae): lost mushroom corals find their way home.

To Cite this Paper: Sawiya., Arfiati, D., Guntur., Ariadi, H., Wafi, A., 2021. Karakter Morfologi Fungiasp. Di Pulau Mamburit, Kabupaten Sumenep, Jawa Timur, Indonesia .Samakia: Jurnal IImu Perikanan, 12 (2): 116-130. 
Budd, A. F., \& Stolarski, J. 2009. Searching for new morphological characters in the systematics of scleractinian reef corals: comparison of septal teeth and granules between Atlantic and Pacific Mussidae. Acta Zoologica, 90(2), 142-165.

Cairns, S. D. 1984. An application of phylogenetic analysis to the Scleractinia: Family Fungiidae. Paper presented at the Fourth International Symposium Fossil Cnidaria, Palaeontographica Americana.

Gittenberger, A., Reijnen, B. T., \& Hoeksema, B. W. 2011. A molecularly based phylogeny reconstruction of mushroom corals (Scleractinia Fungiidae) with taxonomic consequences and evolutionary implications for life history traits. Contributions to Zoology, 80(2).

Hoeksema, B. W. 1989. Taxonomy, phylogeny and biogeography of mushroom corals (Scleractinia: Fungiidae). Zoologische Verhandelingen, 254(1), 1-295.

Hoeksema, B. W. 1990. Evolution of body size in mushroom corals (Scleractinia: Fungiidae) and its ecomorphological consequences. Netherlands Journal of Zoology, 41(2-3), 112-129.

Hoeksema, B. W. 2009. Attached mushroom corals (Scleractinia: Fungiidae) in sediment-stressed reef conditions at Singapore, including a new species and a new record. Raffles Bulletin of Zoology, 22, 81-90.

Hoeksema, B. W. 2012. Distribution patterns of mushroom corals (Scleractinia: Fungiidae) across the Spermonde Shelf, South Sulawesi. Raffles Bulletin of Zoology, 60(1).

Majuro Atoll. 2017. Long-term monitoring guide "coral reef communities and marine debris. The University of Quensand. Australia

Richards, Z. 2019. Hard coral genus identification guide Version 2. The coral compactus: Western Australia

Stella, J. S., Jones, G. P., \& Pratchett, M. S. 2010. Variation in the structure of epifaunal invertebrate assemblages among coral hosts. Coral Reefs, 29(4), 957-973.

Zawada, K. J., Dornelas, M., \& Madin, J. S. 2019. Quantifying coral morphology. bioRxiv, 553453.

To Cite this Paper: Sawiya., Arfiati, D., Guntur., Ariadi, H., Wafi, A., 2021. Karakter Morfologi Fungiasp. Di Pulau Mamburit, Kabupaten Sumenep, Jawa Timur, Indonesia .Samakia: Jurnal IImu Perikanan, 12 (2): 116-130. 